\title{
Melatonin Acts as an Antidepressant by Inhibition of the Acid Sphingomyelinase/ Ceramide System
}

\author{
Richard Hoehn $^{\mathrm{a}}$ Marlene Monse ${ }^{\mathrm{b}} \quad$ Ella Pohl $^{\mathrm{b}}$ Sina Wranik ${ }^{\mathrm{b}}$ Barbara Wilker \\ Simone Keitsch ${ }^{c}$ Matthias Soddemannc Johannes Kornhuber ${ }^{d}$ Marcus Kohnen $^{b}$ \\ Michael J. Edwards ${ }^{a}$ Heike Grassméc Erich Gulbins ${ }^{\mathrm{a}, \mathrm{c}}$ \\ aDept. of Surgery, University of Cincinnati, College of Medicine, University of Cincinnati, Cincinnati, $\mathrm{OH}$, \\ USA; b'Gymnasium Essen-Werden, Essen, 'Dept. of Molecular Biology, Medical School, University of \\ Duisburg-Essen, Essen, dDepartment of Psychiatry and Psychotherapy, University Hospital, Friedrich- \\ Alexander-University Erlangen-Nuremberg, Erlangen, Germany
}

\section{Key Words}

Melatonin $•$ Major depression $•$ Acid sphingomyelinase $\bullet$ Ceramide $・$ Neurogenesis

\begin{abstract}
Background: Melatonin has been shown to have antidepressive effects. We tested whether melatonin inhibits the acid sphingomyelinase/ceramide system and mediates its antidepressive effects via inhibition of the acid sphingomyelinase and a reduction of ceramide in the hippocampus. Antidepressants such as amitriptyline and fluoxetine were previously shown to inhibit the acid sphingomyelinase/ceramide system, which mediates neurogenesis and behavioral changes induced by these drugs. Methods: The effect of melatonin on the activity of the acid sphingomyelinase prior to and after treatment with melatonin was determined in cultured neurons and in vivo in the hippocampus of mice by measuring the consumption of $\left[{ }^{14} \mathrm{C}\right]$ sphingomyelin. Ceramide was measured by DAG kinase assay and fluorescence microscopy of the hippocampus and of cultured neurons. Neurogenesis in the hippocampus was analyzed by in vivo labeling with bromodeoxyuridine. Behavior was assessed in standardized tests. Results: Melatonin treatment inhibited acid sphingomyelinase in vitro in cultured pheochromocytoma cells and in vivo in the hippocampus, which resulted in a reduction of ceramide in vitro and in vivo. The inhibition of the acid sphingomyelinase/ceramide system translated into increased neurogenesis in glucocorticosterone-stressed mice after treatment with melatonin, an effect that is abrogated in acid sphingomyelinase-deficient mice. Likewise, melatonin improved the depressive behavior of stressed mice, a therapeutic effect that was again absent in acid sphingomyelinase-deficient animals. Conclusion: These data indicate that the antidepressive effects of melatonin as well as the induction of neurogenesis triggered by this drug are mediated by an inhibition of the acid sphingomyelinase/ceramide system. This is the first study to identify melatonin as an inhibitor of the acid sphingomyelinase.
\end{abstract}

M. Monse, E. Pohl and S. Wranik, in alphabetical order, contributed equally to the manuscript. 


\section{SịNAis}

Neurosignals 2016;24:48-58

\begin{tabular}{|l|l|}
\hline DOI: 10.1159/000442611 & (c) 2016 The Author(s). Published by S. Karger AG, Basel \\
\hline
\end{tabular}

Published online: July 11, 2016

www.karger.com/nsg

Hoehn et al.: Melatonin Inhibits Acid Sphingomyelinase

\section{Introduction}

Major depressive disorder is a common, morbid disease with a lifetime prevalence of more than $10 \%$ and an estimated suicide rate of $10 \%$ [1]. Common understanding of the disease is centered on a reduced concentration of neurotransmitters in the synaptic space, and many antidepressant medications increase the concentration of monoaminergic transmitters in the synaptic space [2]. This hypothesis was named the monoamine hypothesis for the actions of antidepressants [2]. However, some antidepressants such as tianeptine are also serotonin reuptake enhancers [3] and, most importantly, the delayed onset of the therapeutic action of almost all antidepressants does not fit the immediate increase of monoaminergic transmitters in the synpatic space triggered by these drugs. Thus, alternative concepts for the pathogenesis of major depressive disorder and the action of antidepressants have been developed. These concepts suggest that reduced neurogenesis in the hippocampus is a central element in the pathogenesis of major depressive disorder [4]. Neurogenesis has been shown in the hippocampus of rodents, but also recently confirmed in the hippocampus of humans, with approximately 700 new neurons generated per day and an annual turnover of hippocampal neurons of 1.75\% [5-8]. Two areas in the brain seem to be the hotspots of neurogenesis: the subventricular zone of the lateral ventricles where neuronal stem cells line the lateral ventricle wall and, after proliferation, are able to leave the subventricular zone and migrate into the olfactory bulb and the frontal brain, and secondly the hippocampal dentate gyrus where after proliferation immature neurons migrate into the granular cell layer over a period of 3 to 4 weeks, differentiate into granule cells, form dendrites, and are integrated into the hippocampal networks [5-18].

In accordance, hippocampal atrophy was observed after chronic stress and depression in both rodents and humans [5, 6], suggesting that a decrease of neurogenesis and/or an increase of apoptosis of neurons contribute to the pathogenesis of major depressive disorder. Antidepressants restore neurogenesis and prevent neuronal cell death in primary neural cultures and in the hippocampus of adult rodents [19-24].

We have recently shown that the acid sphingomyelinase/ceramide system is targeted by antidepressants and mediates the neurogenic effects of antidepressants [24]. Acid sphingomyelinase (human protein: ASM, EC 3.1.4.12, sphingomyelin phosphodiesterase; murine protein: Asm, gene symbol Smpd1) is a ubiquitously expressed enzyme that catalyzes the release of ceramide from sphingomyelin [25]. The enzyme localizes to lysosomes, secretory lysosomes and small, acidified domains on the outer leaflet of the plasma membrane $[26,27]$. The generation of ceramide within these domains has been shown to regulate the distribution of receptors and associated proteins in the plasma membrane, a process named receptor clustering or aggregation. Ceramide molecules spontaneously form ceramide-enriched membrane domains that change the biophysical properties of the plasma membrane and thereby serve to trap and cluster receptor and signaling molecules [26-28]. It is this spatial organization of receptors and signaling molecules that mediates many of the signaling effects of Asm and ceramide [26-29]. Thus, the Asm/ceramide system seems to have a general function in the organization of cellular signaling molecules and receptors rather than being a specific signaling intermediate, which also explains the involvement of Asm in many diverse forms of cellular stress [reviewed in 29].

Many antidepressants target the Asm/ceramide system by interfering with the binding of Asm to membranes [30-32]. They mediate a release of the Asm from membranes, which results in the proteolysis of Asm in lysosomes or a release into the extracellular space [32, 33]. Since these antidepressants do not directly interfere with the enzyme activity, they were also named functional inhibitors of Asm, FIASMAs [34]. We have shown that therapeutic concentrations of the antidepressants amitriptyline and fluoxetine functionally inhibit Asm and reduce ceramide concentrations in the hippocampus [24]. The inhibition of the Asm/ ceramide system increased neuronal proliferation, maturation, and survival and improved behavior in models of stress-induced depression [24]. Genetic deficiency of Asm mimicked 
Hoehn et al.: Melatonin Inhibits Acid Sphingomyelinase

the effects of antidepressants and abrogated any further effect of antidepressants on neurogenesis and behavior [24].

We have previously provided a structure-property-activity relation model for the action of antidepressants; we demonstrated that high pKa and high log P values of antidepressants are necessary for functional inhibition of Asm [32, 34, 35]. In addition, a spacer with a protonated nitrogen atom is required to displace the acid sphingomyelinase from the inner lysosomal surface triggering its degradation. Here, we compared these features with the structure of melatonin and whether melatonin inhibits Asm. Our data demonstrate an inhibition of the acid sphingomyelinase by melatonin, but most likely not by a functional inhibition of the acid sphingomyelinase as induced by amitriptyline or fluoxetine, but by other mechanisms.

\section{Materials and Methods}

\section{Mice and treatments}

Wild type and Asm-deficient mice (Smpd1\%) [36] littermates were on a C57BL/6H background. Asmdeficient mice were originally from Dr. R. Kolesnick, Memorial Sloan-Kettering Cancer Center, New York, NY, USA. Asm-deficient mice were used at an age of 6 weeks to avoid sphingomyelin accumulation. Melatonin was dissolved in DMSO and diluted in PBS. $10 \mathrm{mg} / \mathrm{kg}$ were injected twice daily for 12 days [37]. Corticosterone was administered at $0.25 \mathrm{mg} / \mathrm{mL}$ in the drinking water for 14 days. If melatonin and corticosterone were administered together, the corticosterone treatment was started 2 days prior to the application of melatonin. All studies were performed in accordance with animal permissions of the Regierungspraesidium Düsseldorf and the Institutional Animal Care and Use Committee, Cincinnati.

Acid sphingomyelinase activity in cultured cells

Pheochromocytoma cells PC-12 cells were from ATCC and cultured in RPMI-1640 supplemented with 10 mM HEPES (pH 7.4, Carl Roth GmbH, Karlsruhe, Germany), 2 mM L-glutamine, 1 mM sodium pyruvate, $100 \mu \mathrm{M}$ nonessential amino acids, $100 \mathrm{U} / \mathrm{mL}$ penicillin, $100 \mu \mathrm{g} / \mathrm{mL}$ streptomycin (all from Invitrogen) and $10 \%$ fetal calf serum (PAA Laboratories $\mathrm{GmbH}$, Coelbe, Germany). The cell line was maintained at $37^{\circ} \mathrm{C}$ in a humidified atmosphere at $5 \% \mathrm{CO}_{2}$. To treat the cells with melatonin, cells were washed twice in $\mathrm{H} / \mathrm{S}$ (132 mM NaCl, $20 \mathrm{mM}$ HEPES [pH 7.4], $5 \mathrm{mM} \mathrm{KCl,} 1 \mathrm{mM} \mathrm{CaCl}, 0.7 \mathrm{mM} \mathrm{MgCl}{ }_{2}, 0.8 \mathrm{mM} \mathrm{MgSO}_{4}$ ), resuspended at $2 \times 10^{6} / \mathrm{ml}$ in $\mathrm{H} / \mathrm{S}$ and incubated for the indicated time with $50 \mathrm{nM}$ melatonin [37]. Cells were then shockfrozen, thawed, sonicated, and $50 \mu \mathrm{L}$ aliquots were added to $300 \mu \mathrm{L}$ of a buffer consisting of $250 \mathrm{mM}$ sodium acetate (pH 5.0), 0.1\% NP-40 and $50 \mathrm{nCi}\left[{ }^{14} \mathrm{C}\right]$-sphingomyelin per sample (Perkin Elmer, Waltham, MA, USA; $52 \mathrm{mCi} / \mathrm{mmol}$ ). Samples were incubated for $60 \mathrm{~min}$ at $37^{\circ} \mathrm{C}$, the reaction was stopped by addition of 800 $\mu \mathrm{L}$ chloroform/methanol $(2: 1, \mathrm{v} / \mathrm{v})$, phases were separated by centrifugation, aliquots of the upper phase containing the released $\left[{ }^{14} \mathrm{C}\right]$-phosphorylcholine were removed and quantified by liquid scintillation.

\section{Acid sphingomyelinase activity in the hippocampus}

The hippocampus was removed, shock frozen, and lysed in $250 \mathrm{mM}$ sodium acetate (pH 5.0) and 1\% NP40 for $10 \mathrm{~min}$. The tissues were then homogenized by 10 secs sonication using a tip sonicator. Aliquots of the lysates were diluted in $250 \mathrm{mM}$ sodium acetate (pH 5.0) and 0.1\% NP40; incubated with 50 nCi per sample $\left[{ }^{14} \mathrm{C}\right]$ sphingomyelin for $30 \mathrm{~min}$ at $37^{\circ} \mathrm{C}$; and processed as above.

\section{Ceramide measurements}

PC-12 cells ( $2 \times 10^{5} / 200 \mu \mathrm{L}$ in H/S ) were treated with melatonin as above and shock frozen. The hippocampus was removed and homogenized in $200 \mu \mathrm{L} \mathrm{H}_{2} \mathrm{O}$ by tip sonication. Samples were then extracted in $600 \mu \mathrm{L} \mathrm{CHCl}_{3}: \mathrm{CH}_{3} \mathrm{OH}: 1 \mathrm{~N} \mathrm{HCl}(100: 100: 1, \mathrm{v} / \mathrm{v} / \mathrm{v})$. The lower phase was collected, dried, resuspended in $20 \mu \mathrm{L}$ of a detergent solution consisting of 7.5\% (w/v) n-octyl glucopyranoside and $5 \mathrm{mM}$ cardiolipin in 1 mM diethylenetriaminepentaacetic acid (DTPA), and sonicated for $10 \mathrm{~min}$. The kinase reaction was started by the addition of $70 \mu \mathrm{L}$ of a reaction mixture containing $10 \mu \mathrm{L}$ diacylglycerol (DAG) kinase (GE Healthcare Europe, Munich, Germany), 0.1 M imidazole/HCl (pH 6.6), 0.2 mM DTPA (pH 6.6), 70 mM NaCl, 17 mM $\mathrm{MgCl}_{2}, 1.4 \mathrm{mM}$ ethylene glycol tetraacetic acid, $2 \mathrm{mM}$ dithiothreitol, $1 \mu \mathrm{M}$ adenosine triphosphate (ATP), and 
Hoehn et al.: Melatonin Inhibits Acid Sphingomyelinase

$10 \mu \mathrm{Ci}\left[{ }^{32} \mathrm{P}\right] \gamma \mathrm{ATP}$. The kinase reaction was performed for $60 \mathrm{~min}$ at room temperature, terminated by the addition of $1 \mathrm{~mL} \mathrm{CHCl}_{3}: \mathrm{CH}_{3} \mathrm{OH}: 1 \mathrm{~N} \mathrm{HCl}(100: 100: 1, \mathrm{v} / \mathrm{v} / \mathrm{v})$, followed by addition of $170 \mu \mathrm{L}$ buffered saline solution (135 mM NaCl, $1.5 \mathrm{mM} \mathrm{CaCl}_{2}, 0.5 \mathrm{mM} \mathrm{MgCl}_{2}, 5.6 \mathrm{mM}_{\text {glucose, }} 10 \mathrm{mM}$ HEPES [pH 7.2]) and $30 \mu \mathrm{L}$ of a $100 \mathrm{mM}$ EDTA solution. The lower phase was collected, dried, dissolved in $20 \mu \mathrm{L} \mathrm{CHCl}_{3}: \mathrm{CH}_{3} \mathrm{OH}(1: 1, \mathrm{v} / \mathrm{v})$ and separated on Silica G60 thin-layer chromatography (TLC) plates with chloroform/acetone/methanol/ acetic acid $/ \mathrm{H}_{2} \mathrm{O}$ (50:20:15:10:5, v/v/v/v/v). The TLC plates were analyzed by a phospho-Imager. Ceramide amounts were determined by comparison with a standard curve using C16 to C24 ceramides as substrates.

\section{Immunohistochemical analysis of ceramide}

Mice were euthanized, the brains removed, embedded in Tissue-Tek (Sigma) and shock frozen. The hippocampus was then serially sectioned. Frozen sections were dried on air for $5 \mathrm{~min}$, fixed in acetone for 10 min, washed twice in PBS, blocked for 10 min in PBS with 5\% FCS, washed once in PBS and immunostained for 45 min with polyclonal rabbit anti-mouse acid sphingomyelinase antibodies, obtained by immunization with a glutathione-S-transferase (GST) fusion protein (aa 518-564). Antibodies were diluted 1:100 in H/S + $1 \%$ FCS. The samples were then washed 3-times in PBS $+0.05 \%$ Tween 20, once in PBS and incubated for 45 min with Cy3-coupled donkey anti-rabbit IgG (Jackson ImmunoResearch), washed again three times in PBS $+0.05 \%$ Tween 20 and once in PBS, and embedded in Mowiol. Samples were analyzed on a Leica TCS confocal microscope (Leica, Mannheim, Germany).

\section{Immunohistochemical BrdU stainings}

Mice were injected 4-times, every 2 hrs, with $2 \mathrm{mg} / 25 \mathrm{~g}$ bromodeoxyuridine (BrdU). Mice were sacrificed 16 hrs after the last BrdU injection, brains were rapidly removed, shock-frozen, sectioned, air dried and fixed for $10 \mathrm{~min}$ in ice-cold acetone. The samples were then washed, and the DNA was denatured by incubation for $2 \mathrm{~h}$ with $50 \%$ formamide in $300 \mathrm{mM} \mathrm{NaCl}$ and $30 \mathrm{mM}$ saline-sodium citrate (pH 7.0) at $65^{\circ} \mathrm{C}$. The samples were washed twice in saline sodium citrate buffer and the DNA was further denatured for $30 \mathrm{~min}$ at $37^{\circ} \mathrm{C}$ with $2 \mathrm{M} \mathrm{HCl}$. Slides were washed, neutralized for $10 \mathrm{~min}$ with $0.1 \mathrm{M}$ borate buffer (pH 8.5), washed in PBS, and blocked with $0.05 \%$ Tween 20 and 5\% FCS in PBS (pH 7.4). The samples were then stained with $5 \mu \mathrm{g} / \mathrm{mL}$ anti-BrdU antibodies (Roche) for $45 \mathrm{~min}$ at $22^{\circ} \mathrm{C}$, washed, and stained with Cy3coupled $\mathrm{F}(\mathrm{ab})_{2}$ anti-mouse IgG (Jackson ImmunoResearch, Newmarket, UK). Every tenth section of serial sections of the hippocampus was counted for BrdU-positive cells.

\section{Western blots of $P C-12$ cells}

The PC-12 cells were washed in H/S, resuspended in H/S at a density of $0.5 \times 10^{6}$ cells $/ 50 \mu l$, incubated with $50 \mathrm{nM}$ melatonin for the indicated time and lysed in $50 \mu \mathrm{l} 0.1 \%$ SDS, $25 \mathrm{mM}$ HEPES, 0.5\% deoxycholate, 0.1\% Triton X-100, $10 \mathrm{mM}$ EDTA, $10 \mathrm{mM}$ sodium pyrophosphate, $10 \mathrm{mM}$ sodium fluoride, $125 \mathrm{mM} \mathrm{NaCl}$, and $10 \mu \mathrm{g} / \mathrm{ml}$ aprotinin/leupeptin for $5 \mathrm{~min}$ at $4^{\circ} \mathrm{C}$. Insoluble material was removed by centrifugation at $14,000 \mathrm{rpm}$ for $5 \mathrm{~min}$ at $4^{\circ} \mathrm{C}$. The supernatants were removed and added to $5 \mathrm{x}$ SDS-Laemmli buffer. Proteins were separated by $10 \%$ sodium dodecyl sulfate polyacrylamide gel electrophoresis (SDS-PAGE), incubated with either an anti-phospho-Ser-473-Akt antibody or an anti-actin-antibody (both diluted 1:1,000, Cell Signalling) for $1 \mathrm{~h}$ at $22^{\circ} \mathrm{C}$, washed, and developed with alkaline phosphatase-coupled secondary antibodies employing the Tropix chemoluminescence system.

\section{Behavioral studies}

Behavioral testing was performed between 3:00 P.M. and 6:00 P.M. If appropriate, animals were video tracked by a camera. All tests were performed on separate days. Experiments were performed with diffuse indirect room light. Novelty-suppressed feeding: mice were fasted for $24 \mathrm{hrs}$ and then placed in a new cage with one piece of food on a $2 \times 2 \mathrm{~cm}$ piece of white paper in the center of the new environment. The test measures the time during which the mice explored the new environment before they began eating. The light/dark box test measures the time a mouse is present in a dark and safe compartment and a brightly illuminated, open, and thus aversive area. A box made of black acrylic plastic (height, $40 \mathrm{~cm}$ ) was inserted into an open field, covering $50 \%$ of the surface area. A $5 \times 5 \mathrm{~cm}$ aperture led from the light area to the dark box. Each mouse was released in the dark compartment and observed for $5 \mathrm{~min}$. Control experiments showed that the different genotypes did not differ in their locomotion. 
Hoehn et al.: Melatonin Inhibits Acid Sphingomyelinase

\section{Statistical analysis}

All data are given as mean \pm SD. Single comparisons were performed with a student t-test. Multiple comparisons were performed with ANOVA.

\section{Results}

To test whether melatonin inhibits the acid sphingomyelinase and also has an impact on cellular ceramide, we incubated pheochromocytoma PC-12 cells with $50 \mathrm{nM}$ melatonin for 10, 20 and 30 min. The results (Fig. 1) show that melatonin reduced the activity of Asm in cultured cells within 20 min by approximately 30\% (Fig. 1A). This correlated with a reduction of cellular ceramide levels by a similar amount (Fig. 1B). Next, we injected melatonin intraperitoneally into mice twice daily over 10 days and determined the activity of Asm in the hippocampus. These studies (Fig. 2A) confirm the inhibition of Asm by melatonin in vivo and demonstrate a reduction of the hippocampal acid sphingomyelinase activity by approximately $60 \%$. Likewise, the concentration of ceramide in the hippocampus was reduced by approximately $50 \%$ after treatment with melatonin as determined by ceramide kinase assays (Fig. 2B). These biochemical studies were confirmed by staining ceramide in hippocampal sections (Fig. 2C).

Application of glucocorticosterone to stress the mice did not alter the effect of melatonin on Asm and ceramide (Fig. 2A and B).

Collectively, these data establish melatonin as novel inhibitor of the Asm/ceramide system in vitro as well as in vivo.

Recent studies suggest that the beneficial effects of antidepressants are mediated, at least in part, by increased neurogenesis in the hippocampus. We therefore determined neurogenesis in mice treated with melatonin \pm stress. Glucocorticosterone-mediated stress induced a marked reduction of neurogenesis (Fig. 3). The negative effect of glucocorticosterone on neurogenesis in the hippocampus was greatly ameliorated by the application of melatonin (Fig. 3). Melatonin was without effect on basal neurogenesis in the

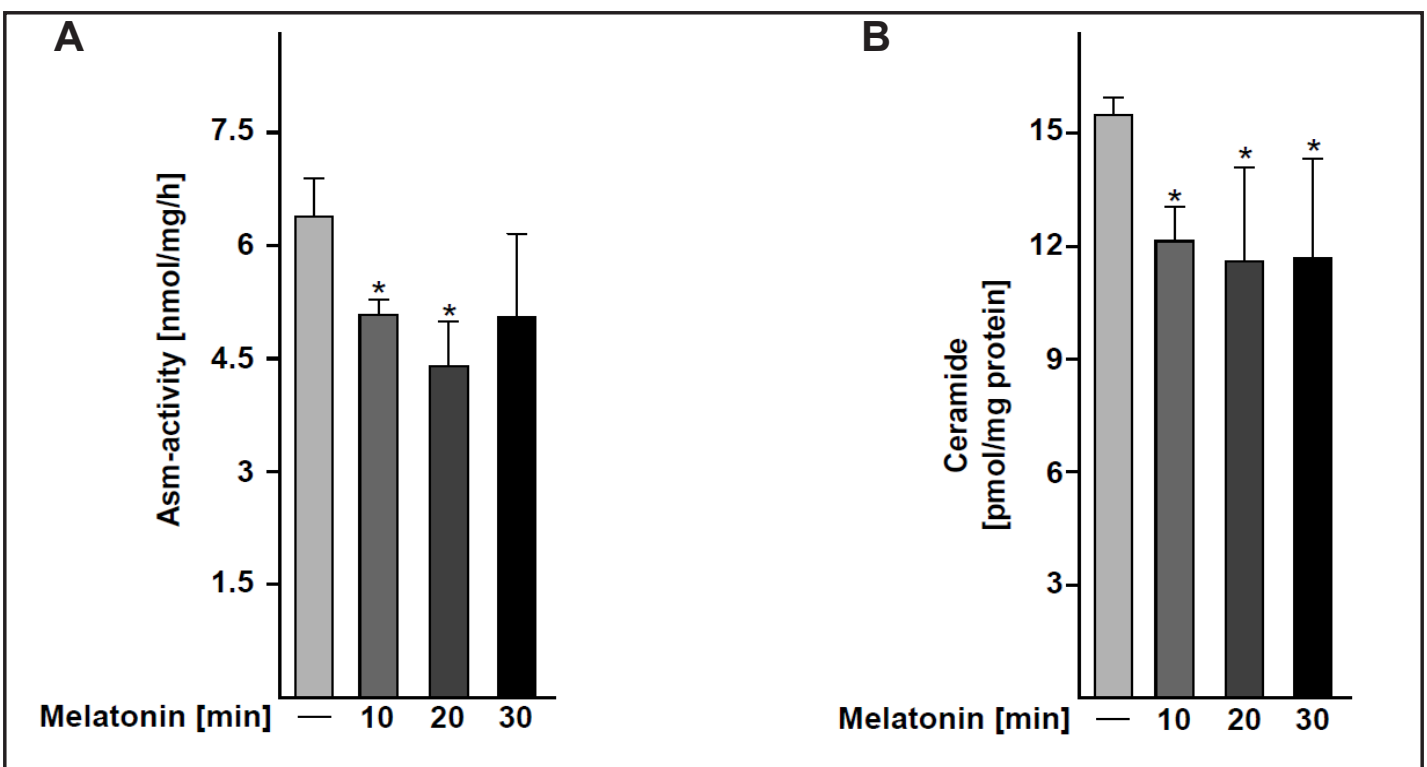

Fig. 1. Melatonin inhibits acid sphingomyelinase and reduces cellular ceramide in vitro. Pheochromocytoma PC-12 cells were incubated with $50 \mathrm{nM}$ melatonin for 10, 20 and $30 \mathrm{~min}$. Activity of the acid sphingomyelinase was determined in cellular extracts by consumption of $\left[{ }^{14} \mathrm{C}\right]$ sphingomyelin. Cellular concentrations of ceramide were analyzed by kinase assays. Shown are the mean \pm SD of three independent experiments. Significant differences compared to untreated controls are indicated by *, $p<0.05$, Anova. 
Fig. 2. Melatonin inhibits acid sphingomyelinase and reduces ceramide in vivo in the hippocampus. Mice tonin at $10 \mathrm{mg} / \mathrm{kg}$ twice daily over 10 days. The hippocampus was removed, shock frozen and the activity of the acid sphingomyelinase (A) and the content of ceramide (B) were measured by biochemical assays as above. Ceramide was also stained in brain sections using a Cy3-coupled monoclonal anti-ceramide antibody (C). Application of glucocorticosterone to stress the mice did not alter the effect of melatonin on acid sphingomyelinase and ceramide (A, B). Shown are mean \pm SD from 3 mice each or a represantative example from 5 mice each. ${ }^{*} \mathrm{p}<0.05$ compared to controls, ANOVA. were injected mela-

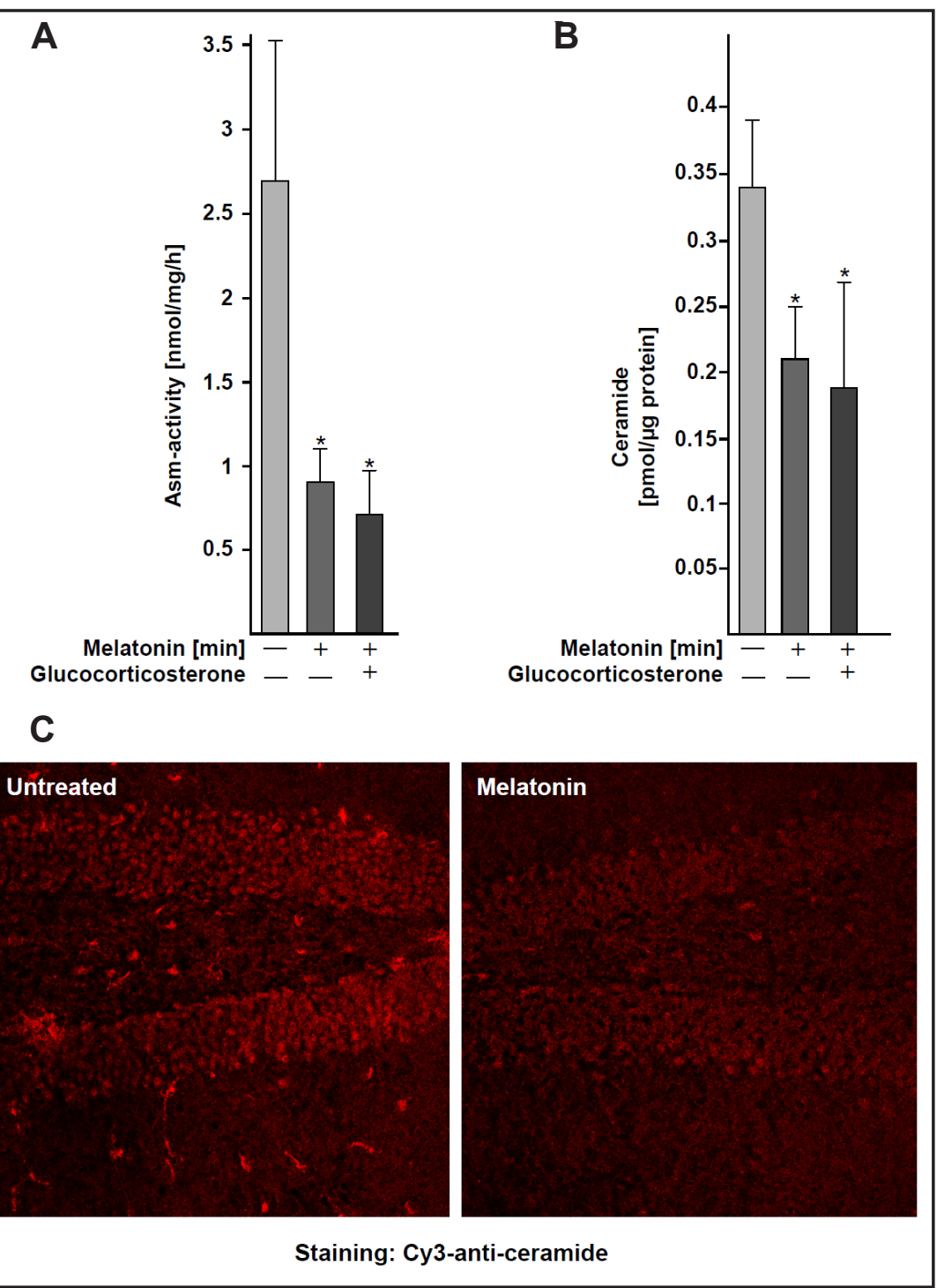

hippocampus (Fig. 3), consistent with previous reports on the effect of antidepressants on neurogenesis in stressed and resting mice [23, 24].

We have previously shown that the positive effect of antidepressants on neurogenesis requires a reduction of ceramide in the hippocampus by inhibition of Asm [20]. The reduction of ceramide by inhibition of Asm reduces the total sum and input of negative stimuli in stressed mice and allows correction of neurogenesis even in the presence of stress, while Asm-deficient mice lost this plasticity [24]. Thus, we treated acid sphingomyelinasedeficient mice with glucocorticosterone and melatonin. These studies revealed that melatonin failed to improve neurogenesis in acid sphingomyelinase-deficient mice treated with glucocorticosterone (Fig. 3).

Next, we tested whether inhibition of the Asm/ceramide system and the induction of neurogenesis in the hippocampus by melatonin also translate into effects on depressed behavior in mice. To this end, mice were stressed by application of glucocorticosterone and treated with melatonin or left untreated. Controls were mice that were injected with the solvent of melatonin, since daily injections also constitute a brief form of stress, or mice left completely untreated. Behavior was tested in the dark-light box and the novelty suppressed feeding test. Glucocorticosterone induced depressive/anxious behavior in both tests compared to untreated or solvent-injected mice (Fig. 4A and B). Application of melatonin 
Fig. 3. Melatonin induces hippocampal neurogenesis via inhibition of the acid sphingomyelinase. Mice were stressed with glucocorticosterone and treated with melatonin or left untreated. Control groups consisted of mice that were completely untreated, received only melatonin or the solvent of melatonin. Stress induced a marked reduction of neurogenesis, which was markedly improved by the application of melatonin. Basal neurogenesis was not affected by melatonin. Serial sections of the hippocampus were counted for the presence of BrdU positive neurons. Shown are mean \pm SD from 5 mice each. $* \mathrm{p}<0.05$ compared to controls, $\Delta \mathrm{p}<0.05$ compared to glucocorticosterone, ANOVA.
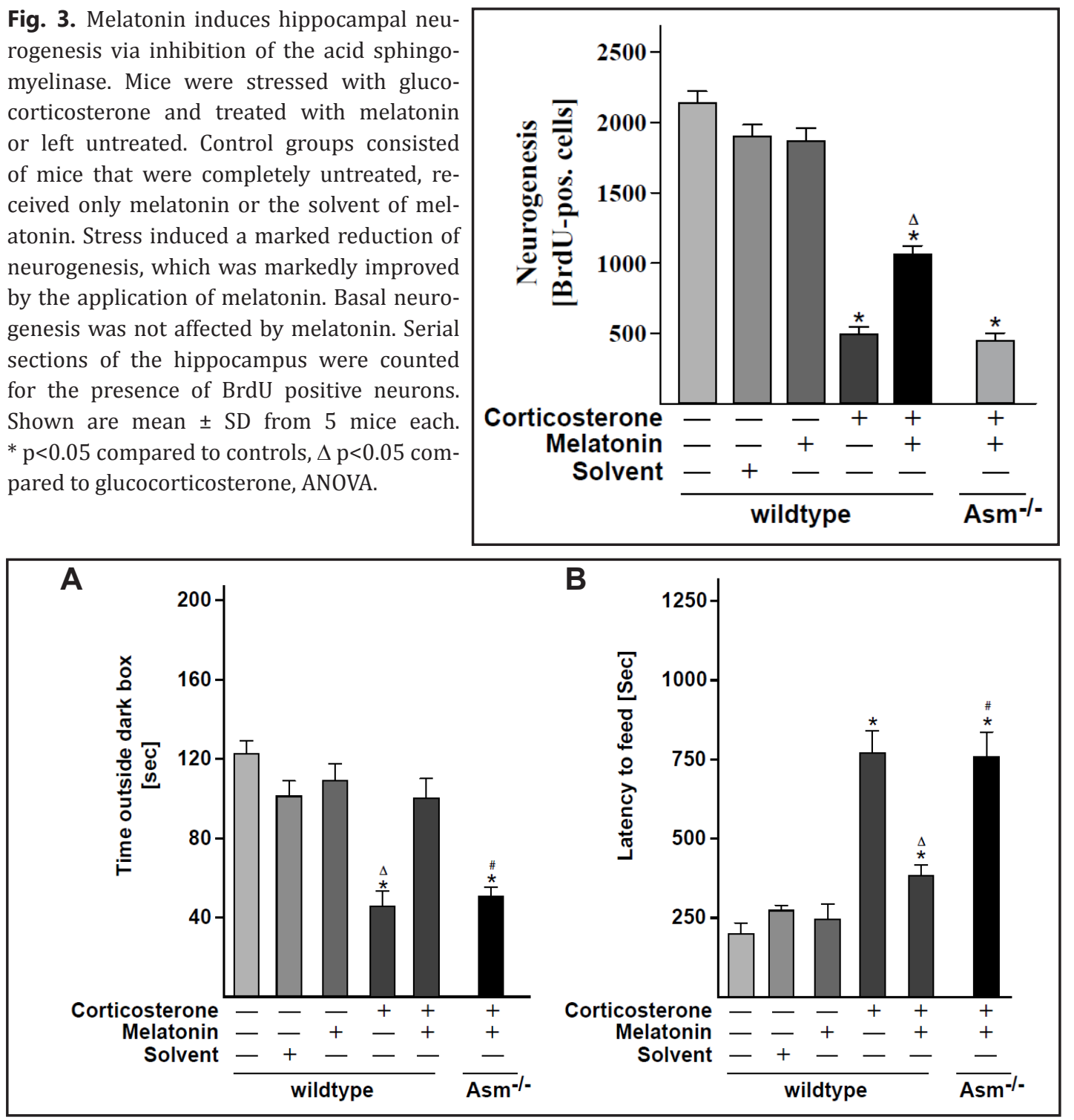

Fig. 4. Melatonin improves behaviour of stressed mice by inhibition of the acid sphingomyelinase/ceramide system. Mice were treated as indicated and outlined above and depressive/anxious behaviour was analyzed by the use of dark-light box and the novelty suppressed feeding tests. Anxious/depressed behaviour of stressed mice was improved by application of melatonin improved in both tests (A and B). Deficiency of the acid sphingomyelinase abrogated the beneficial effects of melatonin on depressive/anxious behaviour of glucocorticoid-stressed mice. Shown are mean \pm SD from 5 mice each. ${ }^{*} \mathrm{p}<0.05$ compared to controls, $\Delta \mathrm{p}<0.05$ compared to glucocorticosterone + melatonin, \# compared to the same group in wt mice, ANOVA.

improved the behavior of stressed mice in both tests (Fig. 4A and B). We have previously shown that mice deficient for Asm respond to stress with depressive and anxious behavior, but are unable to respond to antidepressants since they lost the ability to reduce ceramide in the hippocampus and thereby reduce the sum of negative stimuli in stressed mice. Thus, to prove a role of the Asm/ceramide system for the behavioral effects of melatonin, we stressed Asm-deficient mice and treated them with melatonin. The results show that melatonin was without behavioral effects in stressed Asm-deficient mice (Fig. 4A and B).

These results demonstrate an improvement of depressed and anxious behavior in stressed mice by melatonin, which is mediated by an inhibition of the Asm/ceramide system. 
Finally, we aimed to define downstream targets of melatonin-mediated inhibition of the Asm/ceramide system. We have previously shown [24] that ceramide inhibits the activity and phosphorylation of Akt/PKB. We therefore tested phosphorylation of Akt/PKB in PC-12 cells treated with melatonin. However, while we detected a trend to a rapid activation of Akt/ $\mathrm{PKB}$, which was determined by the phosphorylation of the protein, the differences did not reach statistical significance (not shown).

\section{Discussion}

The present study identifies melatonin as a novel inhibitor of the Asm/ceramide system. The antidepressive effects of melatonin that have been previously described [3840] are mediated by inhibition of Asm and a reduction of ceramide as revealed in genetic studies using Asm-deficient mice. These mice fail to respond to melatonin with changes of the stressed and depressive behavior. We have previously shown that Asm and ceramide are targeted by antidepressants [24]. While direct application of ceramide or geneticallymediated accumulation of ceramide results in reduced neurogenesis and behavioral changes consistent with depression, deficiency of Asm triggers a small constitutive increase of neurogenesis in the hippocampus and behavioral changes in untreated, non-stressed mice [24]. However, Asm-deficient mice fail to respond to antidepressants such as amitriptyline and fluoxetine [24]. These findings are explained by the following model: Basal neurogenesis, and thereby also behavior, is regulated by multiple positive and negative stimuli such as growth factors and glucocorticoids. The balance between these factors controls neurogenesis in the hippocampus. If negative stimuli overweigh the positive stimuli, neurogenesis is reduced until a new balance is created in the hippocampus. Thus, an acute increase of glucocorticoids can be compensated by a decrease of ceramide in the hippocampus resulting in a novel balance between positive and negative stimuli, which allows for normal neurogenesis and behavior. Mice deficient for Asm lost the ability to respond to antidepressants with a reduction of ceramide and thereby fail to compensate the glucocorticoide/stress-induced reduction of neurogenesis and impairment of behavior.

Neurogenesis has been suggested to be a critical event in the pathogenesis of major depression [5-24]. The chronic reduction of neurogenesis might result in a rarefication of neuronal networks and even hippocampal atrophy, events that have been described in major depressive disorder [5, 6]. Antidepressants that increase neurogenesis may not only restore neuronal networks in the hippocampus, but also trigger an increased number of immature neurons that may increase the excitability of the hippocampus, the connections of the hippocampus with the limbic system and provide a negative feedback the hypothalamicpituitary-adrenal axis $[41,42]$, and thereby acutely counteract major depression.

At present it is unknown how inhibition of the Asm/ceramide by melatonin acts within hippocampal neurons to trigger neurogenesis and to improve behavior. Previous studies have suggested Akt/PKB as a target of ceramide, such that antidepressants that reduce Asm activity lead to increased phosphorylation/activation of Akt/PKB and a subsequent increase in hippocampal neurogenesis [24]. However, melatonin did not induce a significant increase of Akt/PKB phosphorylation in PC-12 cells, which may indicate that melatonin is a weak antidepressant. This is also consistent with the moderate effects on neurogenesis and behavior of melatonin that are less pronounced than those of amitriptyline.

Previous studies have revealed structural mechanisms by which antidepressants inhibit Asm; in a structure-property-activity relation model we have identified structural and physicochemical characteristics of compounds that inhibit Asm. FIASMAs are a group of compounds with special physicochemical properties. They possess at least one basic nitrogen atom (most basic pKa value $>4.8$ ) and have moderate to high lipophilicity (logPvalue $>2$ ), and they have no acidic group [32, 34, 35]. These (and some other) properties 
result in accumulation of the FIASMAs in acidic intracellular compartments, insertion into the inner lysosomal membrane and disturbance of the electrostatic interaction between the Asm and the inner lysosomal membrane. The ring system of the drugs allows interaction with the membrane. Asm also binds to the membrane of these acidic compartments. The Asm is then displaced from the membrane and degraded by proteases. This displacement is achieved by a protonated nitrogen atom bound to the ring system via a spacer that allows free presentation of the nitrogen atom. However, melatonin is probably not a FIASMA, because the physicochemical properties (calculated with ACD/LogD Suite 10; Advanced Chemistry Development Inc. Toronto, Canada) of melatonin are different with a $\log \mathrm{P}=0.96$ (not very lipophilic) and the most basic pKa-value $=-0.51$ (not a base). Further, melatonin only mildly inhibits Asm in vitro and does not have the typical physicochemical properties that are common to all known FIASMAs. In particular, the aromatic ring system is small and the introduction of two oxygen atoms on the aromatic ring and the amid-bond in melatonin renders the molecule relatively hydrophilic. The nitrogen atom also looses its basic properties due to the amid bond.

Therefore, the inhibitory effect of melatonin on Asm might be mediated via other mechanisms; e.g. via inhibition of oxidative stress that has been previously reported to be targeted by melatonin [43]. Oxidative stress is a known activator of the Asm [44, 45] and a melatonin-mediated change of the redox-status of the cell might explain the inhibition of the Asm by the drug.

In summary, we have demonstrated that melatonin exerts its antidepressive effects by inhibition of Asm and reduction of ceramide in the hippocampus. This results in increased neurogenesis and improved behavior in stressed mice.

\section{Acknowledgements}

The study was supported to DFG grant GU 335/29-1 to EG, DFG grant DFG: KO 947/131 to JK and BMBF-grant OPTiMD to EG 01EE1401G and JK 01EE1401C. The study was also supported by the GRK 2098 to EG and HG.

\section{Disclosure Statement}

The authors have no conflict of interests to declare.

\section{References}

1 Belmaker RH, Agam G: Major depressive disorder. N Engl J Med 2008;358:55-68.

2 Hirschfeld RM: History and evolution of the monoamine hypothesis of depression. J Clin Psychiatry 2000;61:S4-6.

3 Brink CB, Harvey BH, Brand L: Tianeptine: a novel atypical antidepressant that may provide new insights into the biomolecular basis of depression. Rec Pat CNS Drug Discov 2006;1:29-41.

4 Jacobs BL, van Praag H, Gage FH: Adult brain neurogenesis and psychiatry: a novel theory of depression. Mol Psychiatry 2000;5:262-269.

5 Videbech P, Ravnkilde B: Hippocampal volume and depression: a meta-analysis of MRI studies. Am J Psychiatry 2004;161:1957-1966.

6 Manji HK, Drevets WC, Charney DS: The cellular neurobiology of depression. Nat Med 2001;7:541-547.

7 Ernst A, Alkass K, Bernard S, Salehpour M, Perl S, Tisdale J, Possnert G, Druid H, Frisèn J: Neurogenesis in the striatum of the adult human brain. Cell 2014;156:1072-1083. 
Hoehn et al.: Melatonin Inhibits Acid Sphingomyelinase

8 Spalding KL, Bergmann O, Alkass K, [ Bernard S, Salehpour M, Huttner HB, Boström E, Westerlund I, Vial C, Buchholz BA, Possnert G, Mash DC, Druid H, Frisén J: Dynamics of hippocampal neurogenesis in adult humans. Cell 2013;153:1219-1227.

9 Alvarez-Buylla A, Lim DA: For the long run: maintaining germinal niches in the adult brain. Neuron 2004;41:683-686.

10 Braun SMG, Jessburger S: Adult neurogenesis and its role in neuropsychiatric disease, brain repair and normal function. Neuropathol Appl Neurobiol 2014;40:3-12.

11 Doetsch F, Caillé I, Lim DA, García-Verdugo JM, Alvarez-Buylla A: Subventricular zone astrocytes are neural stem cells in the adult mammalian brain. Cell 1999;97:703-716.

12 Altman J: Are new neurons formed in the brains of adult mammals? Science 1962;135:1127-1128.

13 Altman J, Das GD: Post-natal origin of microneurones in the rat brain. Nature 1965;207:953-956.

14 Kuhn HG, Dickinson-Anson H, Gage FH: Neurogenesis in the dentate gyrus of the adult rat: age-related decrease of neuronal progenitor proliferation. J Neurosci 1996;16:2027-2033.

15 Reynolds BA, Weiss S: Generation of neurons and astrocytes from isolated cells of the adult mammalian central nervous system. Science 1992;255:1707-1710.

16 Bergmann O, Frisén J: Why adults need new brain cells. Science 2013;340:695-696.

17 Sanai N, Nguyen T, Ihrie RA Mirzadeh Z, Tsai HH, Wong M, Gupta N, Berger MS, Huang E, Garcia-Verdugo JM, Rowitch DH, Alvarez-Buylla A: Corridors of migrating neurons in the human brain and their decline during infancy. Nature 2011;478:382-386.

18 Zhao C, Deng W, Gage FH: Mechanisms and functional implications of adult neurogenesis. Cell 2008;132:645-660.

19 D'Sa C, Duman RS: Antidepressants and neuroplasticity. Bipolar Disorder 2002;4:183-194.

20 Malberg JE, Eisch AJ, Nestler EJ, Duman RS: Chronic antidepressant treatment increases neurogenesis in adult rat hippocampus. J Neurosci 2000;20:9104-9110.

21 Sahay A, Hen R: Adult hippocampal neurogenesis in depression. Nat Neurosci 2007;10:1110-1115.

22 Czéh B, Michaelis T, Watanabe T, Frahm J, de Biurrun G, van Kampen M, Bartolomucci A, Fuchs E: Stressinduced changes in cerebral metabolites, hippocampal volume, and cell proliferation are prevented by antidepressant treatment with tianeptine. Proc Natl Acad Sci U S A 2001;98:12796-12801.

23 Santarelli L, Saxe M, Gross C, Surget A, Battaglia F, Dulawa S, Weisstaub N, Lee J, Duman R, Arancio O, Belzung C, Hen R: Requirement of hippocampal neurogenesis for the behavioral effects of antidepressants Science 2003;301:805-809.

24 Gulbins E, Palmada M, Reichel M, Lüth A, Böhmer C, Amato D, Müller CP, Tischbirek CH, Groemer TW, Tabatabai G, Becker KA, Tripal P, Staedtler S, Ackermann TF, van Brederode J, Alzheimer C, Weller M, Lang UE, Kleuser B, Grassmé H, Kornhuber J: Acid sphingomyelinase-ceramide system mediates effects of antidepressant drugs. Nat Med 2013;19:934-938.

25 Jenkins RW, Canals D, Hannun YA: Roles and regulation of secretory and lysosomal acid sphingomyelinase. Cell Signal 2009;21:836-846.

26 Gulbins E, Kolesnick R: Raft ceramide in molecular medicine. Oncogene 2003;22:7070-7077.

27 Grassmé H, Jekle A, Riehle A, Schwarz H, Berger J, Sandhoff K, Kolesnick R, Gulbins E: CD95 signaling via ceramide-rich membrane rafts. J. Biol Chem 2001;276:20589-20596.

28 Grassmé H, Cremesti A, Kolesnick R, Gulbins E: Ceramide-mediated clustering is required for CD95-DISC formation. Oncogene 2003;22:5457-5470.

29 Grassmé H, Riethmüller J, Gulbins E: Biological aspects of ceramide-enriched membrane domains. Prog Lipid Res 2007;46:161-170.

30 Hurwitz R, Ferlinz K, Sandhoff K: The tricyclic antidepressant desipramine causes proteolytic degradation of lysosomal sphingomyelinase in human fibroblasts. Biol Chem Hoppe Seyler 1994;375:447-450.

31 Kölzer M, Werth N, Sandhoff K: Interactions of acid sphingomyelinase and lipid bilayers in the presence of the tricyclic antidepressant desipramine. FEBS Lett 2004;559:96-98.

32 Kornhuber J, Tripal P, Reichel M, Terfloth L, Bleich S, Wiltfang J, Gulbins E: Identification of new functional inhibitors of acid sphingomyelinase using a structure-property-activity relation model. J Med Chem 2008;1:219-237. 
33 Teichgräber V, Ulrich M, Endlich N, Riethmüller J, Wilker B, De Oliveira-Munding CC, van Heeckeren AM, Barr ML, von Kürthy G, Schmid KW, Weller M, Tümmler B, Lang F, Grassme H, Döring G, Gulbins E: Ceramide accumulation mediates inflammation, cell death and infection susceptibility in cystic fibrosis. Nat Med 2008;14:382-391.

34 Kornhuber J, Tripal P, Reichel M, Mühle C, Rhein C, Muehlbacher M, Groemer TW, Gulbins E: Functional inhibitors of acid sphingomyelinase (FIASMAs): a novel pharmacological group of drugs with broad clinical applications. Cel Physiol Biochem 2010;26:9-20.

35 Kornhuber J, Muehlbacher M, Trapp S, Pechmann S, Friedl A, Reichel M, Mühle C, Terfloth L, Groemer TW, Spitzer GW, Liedl KR, Gulbins E, Tripal P. Identification of novel functional inhibitors of acid sphingomyelinase. PLOS ONE 2011;6:e23852.

36 Horinouchi K, Erlich S, Perl DP, Ferlinz K, Bisgaier CL, Sandhoff K, Desnick RJ, Stewart CL, Schuchman EH: Acid sphingomyelinase deficient mice: a model of types A and B Niemann-Pick disease. Nat Genet 1995;10:288-293.

37 Farez MF, Mascanfroni ID, Méndez-Huergo SP, Yeste A, Murugaiyan G, Garo LP, Balbuena Aguirre ME, Patel B, Ysrraelit MC, Zhu C, Kuchroo VK, Rabinovich GA, Quintana FJ, Correale J: Melatonin contributes to the seasonality of multiple sclerosis relapses. Cell 2015;162:1338-1352.

38 Miles A, Philbrick DR: Melatonin and psychiatry. Biol Psychiatry 1988;23:405-425.

39 Kaminski-Hartenthaler A, Nussbaumer B, Forneris CA, Morgan LC, Gaynes BN, Sonis JH, Greenblatt A, Wipplinger J, Lux LJ, Winkler D, Van Noord MG, Hofmann J, Gartlehner G: Melatonin and agomelatine for preventing seasonal affective disorder. Cochrane Database Syst Rev 2015;11:CD011271.

40 Pompili M, Serafini G, Innamorati M, Venturini P, Fusar-Poli P, Sher L, Amore M, Girardi P: Agomelatine, a novel intriguing antidepressant option enhancing neuroplasticity: a critical review. World J Biol Psychiatry 2013;14:412-431.

41 Surget A, Tanti A, Leonardo ED Laugeray A, Rainer Q, Touma C, Palme R, Griebel G, Ibarguen-Vargas Y, Hen $\mathrm{R}$, Belzung C: Antidepressants recruit new neurons to improve stress response regulation. Mol. Psychiatry 2011;16:1177-1188.

42 Snyder JS, Soumier A, Brewer M, Pickel J, Cameron HA: Adult hippocampal neurogenesis buffers stress repsonses and depressive behaviour. Nature 2012;476:458-461.

43 Boutin JA: Quinone reductase 2 as a promising target of melatonin therapeutic actions. Expert Opin Ther Targets 2016;20:303-317.

44 Dumitru CA, Gulbins E: TRAIL activates acid sphingomyelinase via a redox mechanism and releases ceramide to trigger apoptosis. Oncogene 2006;25:5612-5625.

45 Zhang Y, Li X, Carpinteiro A, Gulbins E: Acid sphingomyelinase amplifies redox signaling in Pseudomonas aeruginosa-induced macrophage apoptosis. J Immunol 2008;181:4247-4254. 